\title{
A LINGUAGEM cinematográfica de Wong Kar-Wai: a estética como narrativa nos filmes Amores Expressos e Anjos Caídos ${ }^{1}$
}

Luiza França

Pontifícia Universidade Católica do Rio de Janeiro - PUC-Rio

Departamento de Comunicação Social - Bacharelado em Cinema

\section{Resumo}

Este artigo pretende analisar a linguagem cinematográfica do diretor Wong Kar-Wai, a partir dos filmes Amores Expressos (1994) e Anjos Caídos (1995). O objetivo consiste em compreender como a montagem e a trilha sonora contribuem para a narrativa dos longasmetragens, tendo em vista que Wong Kar-Wai os constrói pautado principalmente na valorização estética, mais do que a própria narrativa em si.

Palavras-chave: cinema; linguagem cinematográfica; estética; narrativa; Wong KarWai.

\section{Introdução}

A pesquisa presente tem como objetivo analisar a linguagem cinematográfica dos filmes de Wong Kar-Wai, especificamente os longas-metragens Amores Expressos (1994) e Anjos Caídos (1995). A partir da montagem e da trilha sonora, será retratado como a linguagem cinematográfica contribui de forma narrativa para os filmes.

Enquanto Wong Kar-Wai filmava Cinzas no Passado (1994), um filme de artes marciais cuja produção estava demorando muito a ser concluída, o diretor começou um esboço do roteiro que daria origem a Amores Expressos (MARIA, 2018). Filmado nos intervalos da gravação do filme de gênero, muitas cenas foram improvisadas e algumas delas acabaram ficando para o filme seguinte do diretor: Anjos Caídos. Apesar de Amores Expressos e Anjos Caídos possuírem enredos diferentes, suas histórias possuem interseções narrativas e principalmente estéticas. Os filmes perpassam por diferentes gêneros, mas apresentam elementos comuns que, em conjunto, constituem uma certa unidade entre eles (CARVALHO, 2004, p. 8).

\footnotetext{
${ }^{1}$ Artigo derivado de monografia de graduação em Cinema, orientada pelo professor Gustavo Chataignier e apresentada em dezembro de 2020.
} 
Também chamado como "esteta" por Gary Bettinson (2015, p. 7 e 58), o diretor chinês organiza todos os parâmetros estilísticos (da montagem e da trilha sonora) para criar um mundo cinematográfico arrebatador que, além de significar por meio da estética, se aproxima do universo imaginário. A partir da análise cênica de ambos os longasmetragens, será explorada a linguagem cinematográfica de Wong Kar-Wai.

\section{A linguagem cinematográfica de Wong Kar-Wai}

O cinema com certeza não é uma língua, ao contrário do que muitos teóricos do cinema mudo disseram ou deram a entender $(\ldots)$, mas é possível considerá-lo como uma linguagem, na medida em que organiza elementos significativos dentro de arranjos organizados, diferentes daqueles que nossos idiomas praticam e que tampouco copiam os conjuntos perceptivos que a realidade nos oferece (...). (METZ apud AUMONT, 2009, p. 184)

Quando o cinema é "capaz de organizar, de construir e de comunicar pensamentos, podendo desenvolver ideias que se modificam, formam e transformam, torna-se então uma linguagem" (MITRY apud AUMONT, 2009, p. 173). A linguagem cinematográfica tradicional, formada pelo cinema clássico, geralmente se limita a um conjunto de receitas, de procedimentos e truques utilizáveis que garantem automaticamente a clareza e eficácia da narrativa (AUMONT, 2009, p. 170). Ou seja, a linguagem tradicional segue um padrão normativo, que por ser amplamente comum e conhecida nas salas de cinema ao redor do mundo, permite que a narrativa seja facilmente compreendida. No entanto, Amores Expressos e Anjos Caídos não se encaixam nessa categoria "linguística", dado que a linguagem cinematográfica de ambos foge desse padrão tradicional, buscando uma inovação estética.

Estabelecendo um contexto histórico do período cinematográfico que os filmes em análise surgiram, o cinema de Wong Kar-Wai faz parte do Cinema Novo de Hong Kong - ou como alguns historiadores também identificam: a Nouvelle Vague de Hong Kong (ZERING, 2015), pela forte influência da Nouvelle Vague francesa. O movimento surge entre as décadas de 1980 e 1990 englobando cineastas como Stanley Kwan, Tsui Hark e Patrick Tam (CARVALHO, 2010, p. 5). Os filmes que marcam esse período foram realizados longe dos grandes estúdios e com uma relação ambígua com as formas tradicionais de narrativa. Porém, sempre estiveram de alguma forma inseridos na indústria local, sem promover qualquer tipo de oposição real a ela. 
Assim como Jean-Luc Godard apostava nos falsos raccords e nos jump-cuts - na ideia de que a "imagem é uma coisa que se desmonta ou remonta" - a linguagem desse novo cinema de Hong Kong também vai se apropriar disso (BEZERRA, 2010, p. 2). Essa geração de cineastas podia experimentar nas suas respectivas linguagens, desde que os filmes respeitassem certas expectativas de gênero, por ser atrativo ao público, e para alcançar um bom retorno financeiro (BEZERRA e FURTADO, 2018, p. 65). O próprio Wong Kar-Wai já falou abertamente que sua capacidade de inovação dentro dos seus filmes é uma tentativa de sobreviver a difícil indústria cinematográfica do país (CHEUNG, 2008, p. 122).

De certa forma, ainda que indiretamente, as condições de uma sociedade ultra capitalista como a de Hong Kong também reflete na construção da linguagem dos filmes do país. Os cineastas recorrem a elementos visuais estilizados e caracterizados de uma forma nãoconvencional para se manterem competitivos no mercado, a fim de surpreender e prender a atenção dos espectadores (CHEUNG, 2008, p. 122). Dentre seus elementos, poder-seiam destacar um ritmo vacilante, o romantismo mais declamado que o sentido, um verdadeiro espetáculo de cores, arquitetura moderna e enquadramentos agressivos (BEZERRA e FURTADO, 2018, p. 71).

É importante identificar o cinema de Wong Kar-Wai no contexto histórico-político do mundo, não só pela influência estética que isso tem em seus filmes, mas pela própria influência na narrativa de Amores Expressos e Anjos Caídos. O Cinema Novo de Hong Kong foi um período marcado significativamente pela volta de Hong Kong para a China, em 1997, mas que não aconteceu de um dia para o outro. Desde 1982, com a visita de Margaret Thatcher a China, começou as conversações para a devolução da soberania de Hong Kong a China (BEZERRA e FURTADO, 2018, p. 72). Essa demora nas negociações do tratado só aumentou a insegurança pela permuta entre a tensa relação com os britânicos, por uma ainda mais incerta com os chineses (BEZERRA e FURTADO, 2018, p. 75). A partir desse momento, os filmes com temáticas sobre a identidade se tornaram mais frequentes nas obras dos cineastas de Hong Kong - incluindo Wong Kar-Wai.

Amores Expressos e Anjos Caídos abordam histórias de personagens que estão em constante dúvidas e incertezas sobre suas ações, e seu lugar no mundo, além de estarem em uma recorrente busca da migração para outro local ou uma mudança de vida, visando o conforto e o pertencimento. Wong Kar-Wai combina diferentes recursos estilísticos para provocar sensações e contemplação, chegando a priorizar mais a estética do que as próprias histórias dos filmes. Ao tentar expressar a narrativa por meio dos elementos 
implícitos da linguagem cinematográfica, o diretor propõe uma experiência "sensorial" a quem assiste.

\section{Amores Expressos e Anjos Caídos: breves sinopses}

Amores Expressos é um filme que se dá em dois atos. O primeiro em que conta a história do policial He, que se esbarra com uma mulher loira (sem nome identificado em nenhum momento do filme), traficante ilegal e por quem He se apaixona. E o segundo ato, em que a história dá lugar para outro policial, identificado como 663, tentando superar o término de um relacionamento duradouro e conhecendo uma jovem atendente da lanchonete que costuma frequentar. São dois policiais, duas mulheres e duas histórias sobre amor que se esbarram, mas não interferem um no outro.

Já em Anjos Caídos, a história dos personagens distintos ocorre em simultaneidade. Desde as ruas e becos escuros de Hong Kong até os pequenos apartamentos entulhados de uma juventude melancólica e solitária, que está sempre à espera de uma companhia amorosa ou mudança de vida, o filme perpassa pela história de personagens que parecem só existir durante a noite. Ming, um matador de aluguel, e He, um jovem mudo que muda de trabalho diariamente, são os principais arcos narrativos que transitam entre si e entre outras pessoas que compõem essa vida noturna. São figuras desajustadas, que em oposição aos personagens banais e comuns de Amores Expressos, narram a rotina das pessoas que vivem na noite de Hong Kong.

\section{O tempo e a narrativa em quebra-cabeças}

A montagem é um dos elementos mais essenciais da linguagem cinematográfica, pois produz sentido para o filme. A combinação das cenas de um filme tem o objetivo de traduzir o roteiro ou a ideia do diretor, mas vai muito além de ser apenas um procedimento técnico e da mera ilustração de uma ideia preexistente. Aumont cita Marcel Martin (2009, p.65) para afirmar que a proposta da montagem cinematográfica é exprimir um sentimento ou uma ideia, a partir do choque de duas imagens. O arranjo dessas imagens é o que constrói a narrativa, produz sentido e expressão na linguagem cinematográfica. Ou seja, a montagem e a narrativa são fatores entrelaçados, complementares um ao outro para um filme ser expressivo. 
O cinema clássico funciona a partir do encadeamento de imagens condicionado por uma lógica racional e que visa principalmente a continuidade dos planos. Aumont afirma que existe um esforço para preservar esses elementos da continuidade (2009, p.77). Em Amores Expressos e Anjos Caídos, a montagem é uma das características mais marcantes - porém, ela faz o caminho inverso dessa montagem que busca uma cadeia contínua, pois Wong Kar-Wai rejeita a continuidade estilística do cinema clássico (RUSHTON apud BETTINSON, 2015. p. 52).

Nas palavras de Alain Robbe-Grillet, autor de longas que se encaixam nessa categoria, os filmes são "disnarrativos" (PARENTE. 2000, p. 131). O cinema disnarrativo não estabelece cronologia e representação linear do tempo pela narrativa, portanto não segue uma lógica sequencial. É assim que os filmes em análise se compõem, com uma montagem que possui um ritmo próprio. A combinação das cenas aparenta acompanhar os pensamentos dos personagens e, por isso, ocorrem frequentes inserções de memórias do passado e devaneios da própria imaginação deles. Essa mistura temporal do presente e passado e a mistura do que é real ou imaginário abre espaço para a dúvida se a cena de fato está acontecendo, se é um sonho ou apenas uma lembrança dos personagens.

Em Amores Expressos, quando o policial 663 aparece em cena com sua ex-namorada, brincando e se beijando dentro do apartamento, temos a impressão de tratar-se de uma memória do passado para o policial - sobretudo pelo fato da ex-namorada quase não aparecer e não termos acesso a nada que diga respeito a ela, exceto pelos relatos pessoais do policial. Ao mesmo tempo que a cena é completamente propícia a ser parte da imaginação e do desejo dele, já que sente falta da relação que não existe mais.

Deleuze (1990, p. 151) afirma que para Alain Resnais, sobre o filme $O$ ano passado em Marienbad (1961), "não eram as personagens que o interessavam, mas os sentimentos que elas podiam extrair (...) as personagens são presentes, mas os sentimentos mergulham no passado". Resnais diz que os sentimentos se tornam os personagens do filme (apud DELEUZE 1990. p. 151). De tal forma, como essa cena do policial com a exnamorada se insere no meio de uma sequência de planos, sem obedecer a uma ordem, a montagem aparenta ser guiada pelo sentimento e memória do policial, que surge subitamente.

A narrativa dos objetos em análise é construída principalmente pelos sentimentos e pensamentos dos personagens do filme, sendo assim, a cronologia é corrompida, não havendo uma sequência orgânica dos acontecimentos. Ela se constrói em cima do 
presente, das lembranças aleatórias que os personagens se recordam ou de seus anseios, como se todos esses cenários estivessem acontecendo simultaneamente.

Os dois filmes apresentam diferentes e característicos personagens, mas a história de cada um deles é sempre recortada ou filtrada, nunca apresentadas as informações narrativas em sua totalidade. A narrativa é construída sem mostrar ou explicar o passado e o futuro desses personagens: não temos acesso aos dados de sua infância, de onde cresceram e sequer de suas famílias, assim como não sabemos o que acontecerá com eles no futuro e qual será o desfecho de suas histórias. Apesar de ocorrerem frequentes inserções de memórias ou devaneios dessas personagens na montagem, isso se realiza a partir de uma escolha, ou seja, há uma manipulação do que é mostrado e esclarecido na narrativa. Até os próprios nomes de alguns personagens não são identificados na trama, como as personagens da mulher loira em Amores Expressos e a parceira de Ming em Anjos Caídos.

A ausência de informações sobre os personagens, que transitam sem um contexto específico e explicativo, desencadeia em um mundo em que as relações são temporárias e os encontros efêmeros se tornam mais importantes do que suas próprias histórias (CARVALHO, 2004, p. 62). Nesse sentido, talvez seja mais adequado definir os encontros como desencontros entre os personagens. He esbarra com a mulher loira no início de Amores Expressos, eles tornam a se encontrar por uma noite e nunca mais se veem. Faye cultiva uma queda amorosa pelo policial 663 e quando finalmente tem a chance de algo acontecer entre eles, ela viaja para o outro lado do mundo. Ming, em Anjos Caídos, se envolve com Punkie, mas logo a deixa, assim como deixou sua parceira de crime para trás. Os caminhos deles se cruzam, mas não tem qualquer tipo de relevância para a história, são só esbarrões casuais.

É como se todas as pessoas fossem passageiras na vida dos personagens, porque sempre anseiam por um recomeço. Partir para outro lugar ou conhecer alguém novo aparenta ser a única opção viável para a mudança que os personagens desejam (CABRAL, 2015). "Não há porto seguro, não há família e é esse sentimento de que não se pertence a lugar algum que é a força motriz, o que faz despertar para uma viagem até o que é próprio de si" (FAUSTO, 2014). Os personagens se deslocam e transitam pela cidade de Hong Kong, de pessoa em pessoa, buscando encontrar algo, alguém ou algum lugar que os preencham. É justamente a transitoriedade e efemeridade que demarca a narrativa de Wong Kar-Wai. A ausência das informações é uma falha narrativa proposital, que permite esse universo da melancolia do ordinário e do deslocamento de corpos - que mesmo em uma cidade lotada de pessoas, os personagens se sentem sozinhos e permanecem se desencontrando. 
Apesar do diretor chinês possuir uma assinatura notável e semelhante entre seus filmes, mistura diferentes técnicas para construir sua linguagem, não se apegando a um "repertório estilístico estável", mas estabelecendo uma unidade em sua filmografia, principalmente nos dois filmes em análise (BETTINSON, 2015, p 49). Tanto em Amores Expressos quanto em Anjos Caídos, a montagem possui um ritmo acelerado, rica em jumpcuts e sincronizada com a trilha sonora. Porém, apesar desses cortes rápidos, os filmes também contam com cenas longas e contemplativas, como planos sequência com a câmera parada, como se a imagem estivesse congelada. O diretor produz modificações na imagem (e no som) dessas cenas prolongadas que remetem a traços da pintura em sua linguagem cinematográfica - provocando uma forte característica apreciativa para as cenas.

Em Anjos Caídos, quando He e Charlie estão em um bar sentados no balcão, a câmera fica estática enquadrando apenas os dois. A cena tem a duração de quase cinco minutos e nela toca apenas uma música, sem nenhum tipo de barulho ou som externo. A música distancia o som verdadeiro do ambiente, já que ela é o único recurso sonoro da cena, sendo que os personagens estão em um restaurante. A cena se torna preta e branca, possui borrões na imagem, com traços semelhantes a uma pintura, por ser menos nítida e com a imagem nebulosa - o que torna a conjuntura cênica ainda mais contemplativa.

Aumont (2009, p. 33) afirma que "embora o pintor seja mais ou menos obrigado a respeitar uma certa lei perspectiva, ele brinca com liberdade com os diversos graus de nitidez da imagem; sobretudo na pintura, o flou, em particular, tem um valor expressivo que se pode usar à vontade". Wong Kar-Wai utiliza dessa perda da nitidez e do foco nas imagens para criar um caráter de apreciação na cena. "Muitos filmes usam o que se chamam às vezes flou artístico" (AUMONT, 2009, p. 33), que é uma perda voluntária do foco em todo o quadro ou em parte dele, para fins expressivos. Ou seja, é mais uma escolha do diretor em alterar a imagem e o som de determinadas cenas para criar esse universo que prioriza o valor estético.

Outro fator da montagem que compõe a narrativa dos filmes, talvez um dos principais da linguagem de Wong Kar-Wai, é a constante repetição de cenas ou situações similares que se reproduzem, "o princípio estrutural do conjunto não está na mudança e no desenvolvimento, mas na repetição" (ABBAS apud CARVALHO, 2004, p. 10). A repetição de cenas serve para reforçar a ideia da rotina dos personagens. Não se sabe sobre as famílias deles, mas é possível conhecer os hábitos e a localidade de cada um. As cenas não são retratadas exatamente da mesma forma, possuem algumas pequenas mudanças 
na diegese como diferentes enquadramentos ou modificações do cenário e do figurino, mas o foco principal é reforçar a ideia do cotidiano monótono. A partir desse artifício, aparecem os personagens no trabalho, em casa, frequentando os mesmos lugares que estão habituados - seja uma lanchonete, como em Amores Expressos, ou em uma pensão, como em Anjos Caídos - mas os locais e as ações se repetem, dando a impressão de um ciclo sem fim.

A maioria dos meus filmes lidam com pessoas que estão presas em certas rotinas e hábitos que não as fazem felizes. Eles querem mudar, mas precisam de alguma coisa para motivá-los. Majoritariamente, eu acho que é o amor que os impulsionam a quebrar essa rotina e seguir em frente. É por isso que sempre queremos repetir as cenas, para mostrar as rotinas deles e as mudanças como acontecem. (KAR-WAI apud BETTINSON. 2015, p. 52 , tradução nossa)

"O cinema de Wong Kar-Wai é um cinema de tempos-mortos, quer dizer, de situações do cotidiano aparentemente banais" (CARVALHO. 2004, p. 63) ou seja, os personagens são figuras comuns, que fazem parte de uma rotina exaustiva assim como qualquer outro. A transformação que anseiam, seja em superar um amor ou viajar para outro lugar, não acontece de um dia para o outro, como uma virada na vida. É preciso de algo que os mobilize a ir atrás dessa reviravolta.

Em Amores Expressos, o policial 663 começa a reparar nas mudanças que Faye passa a fazer escondido em sua casa, mas ainda assim, demora um certo tempo para que ele note essas mudanças graduais nas suas próprias coisas. Isso acontece porque o personagem ainda não está pronto para superar a ex-namorada e se desprender dos objetos antigos. Ele assimila a casa com o seu estado emocional; é como se as coisas de seu apartamento fossem se modificando junto com seus sentimentos, claramente por conta da intervenção de Faye.

Quando o policial chega em casa e encontra o chão completamente alagado, narra o que está pensando naquele momento: "Pensei que sempre seria forte. Nunca imaginei que choraria tanto. Quando choramos, basta pegar num lenço para secar as lágrimas. Mas quando é uma casa a chorar, a cura é muito mais difícil" (AMORES EXPRESSOS, 1994, Wong Kar-Wai). A casa é uma metáfora para os sentimentos do policial, ela sente as coisas assim como ele. É a partir das repetições das cenas dentro desse espaço, e dos sentimentos que vão se modificando, que percebemos quando o policial está finalmente pronto para seguir em frente. 
É importante destacar a narração em off que costura a narrativa de ambos os filmes em análise, os relatos dos personagens são inseridos frequentemente ao longo do filme, são como exposições de seus pensamentos. A voz em off dos personagens, que relata os seus sentimentos e experiências, reforça a ideia da narrativa ser guiada pelo fluxo da consciência deles, como se o filme se passasse no interior de seus pensamentos (CARVALHO, 2004, p. 58). Esse termo "fluxo da consciência", na literatura, foi desenvolvido quando os escritores se tornaram interessados em encontrar caminhos que revelassem as imaginações das vidas íntimas das personagens ficcionais (MOGRABI. 2006, p. 16). O monólogo de cada protagonista "refere-se as narrativas íntimas dos personagens, histórias verdadeiramente mínimas e cotidianas, com características do que, em literatura, seria chamado de crônica" (CARVALHO. 2004, p. 58).

Apesar dos filmes possuírem muito texto e fala, os diálogos - que não são muitos, quando comparados às inserções das vozes dos personagens em off - são sempre banais e não acrescentam muito à narrativa. No entanto, essa ausência de significação contribui para a tentativa do diretor em desnaturalizar a ação dramática. $O$ diretor resiste à supersaturação emocional (BETTINSON, 2015, p. 35) na linguagem de seus filmes, apesar dos temas abordadas serem facilmente hiper dramatizados como o amor, a solidão e a morte. Em Anjos Caídos, de forte influência dos filmes noir, a postura de Ming é baseada na romantização dos galãs inadequados, os anti-heróis, envolvidos com assassinatos e esquemas duvidosos. Porém, ao conhecer as inseguranças, incertezas e pensamentos mais íntimos do personagem através de seus relatos, essa figura premeditada a Ming se quebra.

Não é só a partir da voz em off que ocorre a ruptura da dramatização nos filmes. A partir da construção da linguagem e narrativa, fica claro que o amor é o elemento que norteia a maioria dos personagens: eles sofrem por alguma paixão passada ou estão em busca de uma nova companhia amorosa. Todos eles revelam indícios de carência em algum momento, mas a quebra dessa dramatização de uma grande história de amor acontece quando o diretor castra o espectador das resoluções amorosas. Ele não permite acesso ao que vai acontecer em seguida, deixando em aberto ou passando batido, como algo corriqueiro da vida. Na cena em que o policial 663 e Faye finalmente se encontram, depois de um ano, a expectativa é que algo aconteça entre eles e é exatamente nesse momento que o filme termina. Roland Barthes (apud AUMONT, 2009, p. 125) via o paradoxo de qualquer narrativa diante a solução e ao final da história de um filme: levar à revelação final ou deixá-la sempre para depois? Wong Kar-Wai estrategicamente sempre a deixa para depois, optando por não revelar os desfechos dos personagens. 
O crítico Stephen Teo argumenta que "os elementos-chave do cinema de Wong - o que críticos mais velhos chamariam de 'atmosfera' ou 'caracterização' - são fundados na abstração visual mais do que no enredo propriamente dito" (apud CARVALHO, 2004, p. 52). Esse embaralhamento temporal da linguagem cinematográfica, que se assemelha a estrutura de um quebra-cabeças, funciona como uma estratégia narrativa, em que uma está atrelada a outra, mas a plasticidade dos filmes pode prevalecer a própria diegese.

\section{A estética dos videoclipes e as músicas narrativas}

Segundo Michel Chion, o som no cinema, mais do que a imagem, é um meio insidioso de manipulação afetiva e semântica, "no som, há sempre qualquer coisa que nos submerge e nos surpreende" (2011, p. 33). Para o autor, o som interpreta o sentido da imagem e nos faz ver aquilo que sem ele não veríamos, ou que veríamos de outra forma (CHION, 2011, p. 33). Sendo assim, o papel do som produz uma percepção única das cenas, que reflete diretamente na forma que o espectador recebe e interpreta os filmes, se tornando um artifício indispensável para a experiência do cinema.

Os filmes Amores Expressos e Anjos Caídos utilizam recursos de montagem semelhantes à estética dos videoclipes e isso se deve significativamente pela trilha sonora. O que marca a conexão entre a linguagem dos filmes de Wong Kar-Wai e a estética desses vídeos musicais é o desprendimento da continuidade temporal e o ritmo da montagem em sincronia com a trilha sonora, que segundo Chion "permite a imagem passear-se à vontade no tempo e no espaço" (CHION, 2011, p. 68). Os filmes em análise utilizam dessa montagem ritmada e guiada pela trilha sonora em diferentes momentos para reforçar a descontinuidade temporal que as histórias se constroem. Segundo Howard Hampton, citado por Gary Bettinson, os filmes do diretor chinês constituem uma "síntese incrível hábil do cinema arte e a MTV" (2015, p. 29, tradução nossa), ou seja, uma hibridização dos discursos do cinema como arte e a estética MTV, que se refere aos videoclipes.

Ambos os longas-metragens compartilham uma cena que é construída de forma semelhante: no mesmo cenário, com uma montagem frenética, mas com os respectivos personagens de cada filme. Em Amores Expressos, a cena possui uma montagem que acompanha o barulho dos passos da personagem em foco: a cada passo, um corte - em sincronia com a música de fundo. Com a câmera na mão, cada plano mostra um diferente enquadramento, portanto, há uma variação exacerbada dos ângulos. Essa construção cênica dá a impressão de que o fotógrafo está tentando acompanhar o ritmo da 
personagem, isto é, o ritmo da trilha. Em Anjos Caídos, a edição se constrói de maneira parecida, com os mesmos recursos estilísticos.

É possível estabelecer relação entre essa forma de montagem com um exemplo citado por André Berthomieu no livro de Aumont $A$ estética do filme: "saltar de um plano de conjunto a um primeiro plano pode constituir um erro voluntário que atrai a atenção do espectador pelo inesperado e pelo choque visual" (2009, p. 167). Ou seja, o que pode ter aparentado como um erro de montagem, causa um impacto visual diferente na linguagem dos filmes, que prende a concentração de quem está assistindo.

O quadro é o que faz com que a imagem não seja infinita: o que termina a imagem, o que a detém (AUMONT, 2004, p. 112), ou seja, limita o que será mostrado. Entretanto, o som liberta o cinema desse confinamento, porque não existe um contentor sonoro, como o quadro que limita as imagens. Embora o som possua uma fonte, ele não detém uma localização, isto é, ele pode vir de algum lugar particular, mas preenche completamente o espaço no qual é ouvido (SHAVIRO, 2015, p. 17). De tal forma, é possível sobrepor diferentes sons desejados uns sobre os outros, simultaneamente e sem qualquer limitação (CHION, 2011, p. 59). Com a possibilidade de explorar diferentes pistas de áudio, Wong Kar-Wai combina diferentes sons buscando ambientar os cenários, construir a narrativa e enriquecer a percepção estética.

Um dos pontos mais cruciais da trilha sonora dos filmes em análise é a música. Wong KarWai integra as músicas na narrativa e diegese dos filmes (BETTINSON, 2015, p. 29), estabelecendo a partir da linguagem, informações expressivas da história pela trilha sonora. Segundo Bettinson (2015, p. 34, tradução nossa) "quando a expressividade do personagem não está disponível, o peso da expressão recai sobre outros dispositivos diegéticos ou estilísticos" - que no caso, são as músicas dos filmes.

A trilha sonora dos filmes é composta por músicas específicas que acompanham a trajetória dos personagens e refletem traços da personalidade ou os sentimentos deles na tela. Cada personagem é individualizado por um tema musical diferente, possui seu "próprio ambiente sonoro" (MARTINEZ apud BETTISON, 2015, p. 34), que condiz com sua história. Esses temas musicais se repetem com frequência ao longo dos filmes, por acompanharem os personagens em cena, criando porções narrativas individuais dentro da própria narrativa (CARVALHO, 2004, p. 65). Ou seja, diferentes narrativas dentro de uma só. Com isso, é reforçada a ideia de que não existe uma única história principal nos filmes, 
já que a de cada personagem acontece em paralelo, mudando o foco central da narrativa constantemente.

Em Amores Expressos, a música mais tocada é California Dreaming, do grupo musical estadunidense The Mamas \& The Papas. O hit acompanha a personagem Faye, a jovem que sonha em viajar para a Califórnia, se desprender da rotina pacata e viver novas experiências. No próprio nome da música é possível perceber a relação que se estabelece com a história da personagem: "o sonho Californiano" (BETTINSON, 2015, p. 29). A música fala sobre alguém que quer partir para Los Angeles, onde sabe que se sentirá protegido e aquecido. Faye acredita e anseia justamente por essa partida, de sair de onde se encontra e recomeçar nem que seja em outro continente.

No caso de Anjos Caídos, a música mais emblemática do filme é a que acompanha Ming, o assassino de aluguel: um remix da música Karmacoma, do grupo inglês Massive Attack. A música tem diferentes variações e inserções de instrumentos, mas ela se mantém em um ritmo constante, sem nunca atingir um clímax. Chion afirma que "um ritmo demasiado regularmente cíclico pode também criar um efeito de tensão, uma vez que se pode antever nessa mesma regularidade mecânica a possibilidade de uma flutuação" (2011, p. 19) e a principal função dessa música é provocar tensão em cena, principalmente porque ela se repete nos momentos em que Ming realiza algum assassinato. Karmacoma é uma espécie de monólogo de alguém que não quer compromisso, mas gosta de se sentir desejado, assim como a relação que Ming estabelece com sua parceira de crime. O nome da música pode até ser encarado como uma "pista" narrativa (BORDWELL apud BETTINSON, 2015, p. 46) levando em consideração o termo hindu conhecido como karma, baseado no princípio de que as ações de uma pessoa retornam para ela - assim como Ming, que trabalhava matando pessoas e acabou sendo morto ao final do filme.

A trilha sonora explora contextos musicais internacionais (da Europa e dos Estados Unidos) e contextos musicais inter-regionais (de Taiwan e outros territórios asiáticos) (BETTISON, 2015, p. 32). As músicas refletem a imagem de Hong Kong e a população que habita os filmes, extremamente influenciada pelo Ocidente. Além das frequentes referências aos elementos da cultura ocidental como a aparição da franquia McDonalds, símbolos da CocaCola e os próprios nomes de alguns personagens serem em inglês (CARVALHO, 2004, p. 112). Bérénice Reynaud, citada por Ludmila Carvalho (2010, p. 2), afirma que: "desde o início, fruto da colaboração entre capital estrangeiro e criatividade local, filmado com material e películas importadas, este cinema é híbrido, a meio-caminho entre Oriente e Ocidente". Portanto, a partir dessa mistura localista das músicas presentes nos filmes em 
análise, é possível enxergar como as influências e características do cinema de Hong Kong são integradas na linguagem cinematográfica de Wong Kar-Wai - como algo "fragmentado, problemático e transnacional" (CARVALHO, 2010, p. 5).

É importante pontuar uma função indispensável em Amores Expressos e Anjos Caídos, a mixagem de som. O papel da mixagem é apurar e equilibrar a montagem sonora, ou seja, fundir as camadas de sons existentes de uma forma harmonizada e natural (REVERB, 2019). A partir dessa função, é possível colocar um som em primeiro plano, fazer com que um áudio pareça próximo ou distante, além de outros efeitos. Enquanto acontece a narração dos personagens em off, as músicas tocam simultaneamente e ocorre uma variação no volume dos sons - de modo que todo som ambiente, que está sobreposto a narração e a música, ficam distantes, como uma espécie de eco. Além de isolar os áudios que são mais importantes para a narrativa em determinado momento, esse recurso também rompe com o estilo de som diegético como conhecemos - e com isso, muda a percepção sonora do espectador. O trabalho de mixagem e edição do som faz com que, em determinadas cenas, as músicas se tornem o elemento sonoro principal, em que todas as faixas de áudios diegéticos que ambientam a cena desapareçam. Sendo assim, sem o som diegético ou a narração em off dos personagens para explicitar a história, a música se torna o único recurso narrativo em tela, se aproximando ainda mais da construção dos vídeos musicais.

A partir da relação que se estabelece entre as histórias dos personagens e as músicas é possível ver como a trilha sonora funciona como significado de expressão para a narrativa. São as músicas que os personagens se apegam que os possibilitam reconhecer em si mesmos o que sentem em relação a si, ao mundo e ao outro - e de expressar estes sentimentos (MONASSA, [201-?]). Dessa forma, as músicas atuam de forma implícita e sintomática na narrativa dentro dos filmes de Wong Kar-Wai (BETTISON, 2015, p. 17), sugerindo informações das histórias dos personagens. "O clipe conta uma história, por mais confusa e fragmentada que seja, cuja trama tem a ver com a canção: é onde se mantém a ligação com o cinema enquanto narrativa-em-imagens" (LIPOVETSKY apud OLIVA, 2013), ou seja, a música é ponto em comum entre a linguagem cinematográfica e a estética dos videoclipes. São as diversas músicas que "organizam o ritmo e a dança das imagens, em um casamento totalmente videocliptico", marcando o movimento frenético dos personagens solitários de Hong Kong (MONASSA, [201-?]). 


\section{Considerações finais}

A linguagem cinematográfica utilizada por Wong Kar-Wai é construída, pautada na valorização estética, buscando a contemplação visual e sonora tanto quanto o significado da narrativa. Em meio ao cinema internacional que dispõe de tantas linguagens diferentes, é importante conhecer métodos e formas inovadoras de fazer cinema, que não se encaixam no tradicional, isto é, que normalmente busca pelo naturalismo na tela.

Para Aumont, qualquer filme pode ser definido como um espetáculo e apresentar um caráter fantástico, e é justamente a partir do momento que um filme se transforma em espetáculo que a porta está aberta para o devaneio. O que não exclui a reflexão séria em cima do conteúdo cinematográfico, mas ao mesmo tempo só requer do espectador o ato de receber as imagens e os sons (AUMONT, 2009, p. 100 e 101), como se estivesse em um estado onírico. Aumont ainda ressalta que a preocupação estética de um filme - ou espetáculo - tende sempre a transformar o objeto bruto em objeto de contemplação, em "visão" que se aproxima mais do imaginário do que o real (2009, p. 101).

No caso da linguagem cinematográfica de Amores Expressos e Anjos Caídos, se aproxima muito mais de um universo imaginário que assume o papel como obra do cinema, do que da representação do realismo. A chave disso está na concentração dos detalhes de Wong Kar-Wai: montagem livre de esboços, experimentação com imagens, e a presença desconectada dos personagens que estão nos filmes sem serem inscritos em uma estrutura dramática clara, faz com que o filme se pareça com um sonho. (BOTZBORNSTEIN, 2007, p. 78).

Como a imagem é limitada pelo quadro - ou melhor, pela tela - parece que estamos captando apenas uma porção desse espaço. Essa porção de espaço imaginário que fica contida dentro da tela se chama campo (AUMONT, 2009, p. 21). Portanto, o fora de campo é definido como o conjunto de elementos que não estão inseridos na tela, mas são passíveis do imaginário do espectador por ser vinculado ao que aparece em campo (AUMONT, 2009, p. 24). Para Aumont, o que está dentro da tela, dentro do campo, é a reserva do imaginário, o reino da fiç̧ão (2004, p. 40). Quando Wong Kar-Wai utiliza de diferentes recursos imagéticos para projetar exatamente o que aparece em tela (e incentivar o imaginário que está fora de campo), ele propõe um convite ao espectador para o mundo da ficção: isto é um filme, aproveite. 
A construção de Amores Expressos e Anjos Caídos é toda pautada na estética da contemplação visual e sonora da atmosfera meticulosamente produzida por Wong KarWai, e isso ocorre também pelo afastamento do naturalismo. Como vimos anteriormente, o diretor chinês experimenta diferentes recursos em sua linguagem cinematográfica, principalmente na montagem e na trilha sonora, com uma estética desprendida do espaçotempo e músicas que se soltam dos emissores e invadem as cenas. De acordo com Aumont, o cinema transporta o sujeito para a ficção, para o imaginário, para o sonho e também para outro espaço onde as inibições são, parcialmente, sanadas (2004, p. 53), é nesse cinema que os filmes em análise sem encaixam.

"Não sei explicar meus filmes. Se o soubesse, por que eu filmaria?" questiona Wong KarWai (KAR-WAI apud FOLHA DE S. PAULO, 1998). Amores Expressos e Anjos Caídos são filmes que expõem suas narrativas por meio de suas formas - o que pode causar uma certa interferência na compreensão integral da narrativa. Porém, além da proposta ser justamente o mergulho na estética das imagens e dos sons, ao deixar as narrativas em aberto, Wong Kar-Wai também propõe a livre interpretação do espectador para as histórias dos filmes. Como diria Godard, em História(s) do Cinema (1988): "que maravilha é poder olhar aquilo que não se vê", exaltando o que é invisível aos olhos, por ser enxergado apenas pelo imaginário pessoal de cada espectador com a obra.

\section{Referências bibliográficas}

AUMONT, Jacques. A estética do filme. 7a edição. São Paulo: Papirus Editora, 2009.

AUMONT, Jacques. O olho interminável: cinema e pintura. Cosac \& Naify, 2004.

BETTINSON, Gary. The Sensuous Cinema of Wong Kar-Wai: Film Poetics and the Aesthetic of Disturbance. Hong Kong: Hong Kong University Press, 2015.

BEZERRA, J; FURTADO, F. Cidade em chamas: O cinema de Hong Kong. Rio de Janeiro: Editora Firula, 2018.

BOTZ-BORNSTEIN, Thorsten. Films and Dreams: Tarkovsky, Bergman, Sokurov, Kubrick and Wong Kar-Wai. Estados Unidos: Lexington Books, 2007.

CABRAL, Luana Mendonça. Sobre o corpo e Seu Espaço: Trânsito e Interculturalidade em Amores Expressos. Associação Brasileira de Cinematografia, 2015. Disponível em: https://www.abcine.org.br/artigos/?id=1572\&/sobre-o-corpo-e-seu-espaco-transito-einterculturalidade-em-amores-expressos. Acesso em 2020.

CARVALHO, Ludmila Moreira Macedo. A poética dos Anjos Caídos: um estudo sobre o cinema de Wong Kar-Wai. Salvador: UFBA, 2004. 
CARVALHO, Ludmila Moreira Macedo. O cinema de Hong Kong: do local ao transnacional. Salvador: Fazendo Gênero 9, 2010.

CHEUNG, Wai Yee Ruby. Hong Kong Cinema 1982-2002: the quest for identity during transition. Saint Andrews: University of St. Andrews, 2008.

CHION, Michel. A audiovisão: som e imagem no cinema. Lisboa: Edições Texto \& Grafia, 2011.

DELEUZE, Gilles. A imagem-tempo. São Paulo: Editora Brasiliense, 1990.

FAUSTO, Juliana. No clima para Wong Kar-Wai. Revista Contracampo, 2014. Disponível em: http://www.contracampo.com.br/21/wong.htm. Acesso em 2020.

FOLHA DE S. PAULO. Wong Kar-Wai. 1998. Disponível em: https://www1.folha.uol.com.br/fsp/mais/fs01039811.htm. Acesso em 2020.

MARIA, Fernanda. Neon, noite e solidão por Wong Kar-Wai. 2018. https://medium.com/@femar1a/neon-noite-e-solid\%C3\%A3o-em-wong-kar-waic31e2b587100. Acesso em 2020.

MOGRABI, Alexandre Nascimento. A travessia de A Barca dos Homens de Autran Dourado nas ondas do fluxo de consciência. Juiz de Fora: Centro de Ensino Superior de Juiz de Fora, 2006.

MONASSA, Tatiana. Lovesong. Contracampo: revista de cinema, [201-?]. Disponível em: http://www.contracampo.com.br/66/lovesongtatiana.htm. Acesso em 2020.

OLIVA, Rodrigo. Um caminho duplo de interferência: reflexões sobre interações entre a linguagem cinematográfica e a linguagem do videoclipe. Rua: Revista universitária do audiovisual. Disponível em: http://www.rua.ufscar.br/um-caminho-duplo-deinterferencia-reflexoes-sobre-interacoes-entre-a-linguagem-cinematografica-e-alinguagem-do-videoclipe/. Acesso em 2020.

PARENTE, André. Narrativa e modernidade: os cinemas não-narrativos do pós-guerra. Campinas: Papirus Editora, 2000.

REVERB. Oscar: qual a diferença entre edição de som e mixagem de som? 2019. Disponível em: $\quad$ https://reverb.com.br/artigo/oscar-qual-a-diferenca-entre-edicao-de-som-emixagem-de-som. Acesso em 2020.

SHAVIRO, Steven. Splitting the Atom: articulações pós-cinemáticas do som e da visão. 2015.

ZERING. A nova onda de Hong Kong, mesmo para os burros. CinéLouge, 2015. Disponível em:

http://archive.wikiwix.com/cache/index2.php?rev t=1606679447\&url=https://www.cine lounge.org/gazar/2/-/com-20. Acesso em 2020. 


\section{Filmografia}

AMORES Expressos. Diretor: Wong Kar-Wai. Hong Kong. 1994.

ANJOS Caídos. Diretor: Wong Kar-Wai. Hong Kong. 1995.

O ANO Passado em Marienbad. Diretor: Alain Resnais. Paris. 1961.

HISTÓRIA(S) do Cinema. Diretor: Jean Luc-Godard. Paris. 1988. 